\title{
A imagem a serviço do conhecimento: um estudo sobre a ilustração científica no Instituto Oswaldo Cruz
}

The image in the service of knowledge: a case study on scientific drawings in the historical archives in the custody of the Casa de Oswaldo Cruz

1.

Doutora em História Social pela Universidade de São Paulo, chefe do Departamento de Arquivo e Documentação/Casa de Oswaldo Cruz/Fiocruz.. E-mail: aline. lacerda@fiocruz.br

2.

Doutora em História da Ciência pelo Programa de Pós-graduação em História das Ciências e da Saúde, pesquisadora da Casa de Oswaldo Cruz/Fiocruz. E-mail: ana.girao@fiocruz.br

3.

Mestre em História pela

Universidade Federal do Rio

Grande do Sul, pesquisador da

Casa de Oswaldo Cruz/Fiocruz.

E-mail: felipe.vieira@fiocruz.br

4.

Mestre em Comunicação pela Universidade Federal

Fluminense, pesquisador da

Casa de Oswaldo Cruz/Fiocruz.

E-mail: francisco.lourenco@

fiocruz.br

5.

Mestre em Ciência da

Informação pelo Instituto

Brasileiro de Informação em

\author{
Aline Lopes de Lacerda ${ }^{1}$ \\ Ana Luce Girão Soares de Lima² \\ Felipe Almeida Vieira ${ }^{3}$ \\ Francisco dos Santos Lourenço ${ }^{4}$ \\ Regina Celie Simões Marques ${ }^{5}$
}

\section{Resumo}

Apresenta projeto de pesquisa em curso, configurado como estudo de caso, cuja finalidade é investigar as funções da ilustração científica realizada no Instituto Oswaldo Cruz (IOC) e propor metodologia de descrição desses documentos. Delineia o objeto empírico do estudo - desenhos entomológicos das décadas de 1900 a 1980 pertencentes ao arquivo do Instituto e de dois de seus pesquisadores -, abordando-o sobretudo na sua condição de desenho científico e na perspectiva de seu contexto de produção. Indica as diretrizes e perspectivas metodológicas adotadas, bem como os resultados até agora obtidos na prospecção das fontes documentais.

\section{Palavras-chave}

ilustração científica; entomologia; arquivos científicos; documentos iconográficos; Instituto Oswaldo Cruz.

\section{Abstract}

TPresents the research project in progress, a case study, which aims to explore the role of scientific 
Ciência e Tecnologia, chefe do Serviço de Arquivo Histórico/ Departamento de Arquivo e Documentação/Fiocruz. E-mail: regina.marques@fiocruz.br.

6.

0 projeto obteve o apoio do CNPq, por meio de edital Fiocruz/COC/CNPq em 2015, com prazo de três anos de desenvolvimento. illustration in the works developed by the Oswaldo Cruz Institute (IOC) and to propose methodology for describing these documents. Outlines the empirical object of the study - entomological drawings of the decades of 1900 to 1980 - approaching it mainly in its condition of scientific drawing and from the perspective of its production context. Indicates the guidelines and methodological perspectives adopted, as well as the results obtained so far in the exploration of documentary sources.

\section{Keywords}

scientific illustration; entomology; scientific archives; iconographic documents; Oswaldo Cruz Institute..

\section{Introdução}

Será apresentado o projeto de pesquisa "A imagem a serviço do conhecimento: estudo de caso sobre desenhos científicos nos arquivos históricos sob a guarda da Casa de Oswaldo Cruz"6, que tem por finalidade investigar as funções da ilustração científica nos trabalhos desenvolvidos pelo Instituto Oswaldo Cruz (IOC) nos seus cem primeiros anos. Pretende, ainda, apresentar uma reflexão sobre o tema à luz dos levantamentos documentais realizados em seu primeiro ano de atividades.

Esse tipo de recurso ilustrativo - o desenho - foi amplamente explorado pelo IOC, ao lado de outras espécies de representações visuais como fotografias, filmes e mapas. A maior evidência da relevância desses trabalhos na trajetória do Instituto é o amplo conjunto de ilustrações, na forma de desenhos em várias técnicas, preservados e que atualmente integram arquivos históricos sob a guarda do Departamento de Arquivo e Documentação da Casa de Oswaldo Cruz/Fiocruz (DAD). Esse corpus empírico é o ponto de partida do trabalho de pesquisa proposto e em desenvolvimento.

A elaboração do projeto citado foi norteada pela necessidade de dotar os desenhos de informações contextuais que auxiliassem a compreensão de sua gênese, de seus circuitos de uso, das lógicas que 
orientaram sua produção e publicação, seu papel na formação do texto científico e suas relações com os outros recursos discursivos utilizados no desenvolvimento e comunicação das pesquisas, além de suas relações com as coleções científicas.

0 objeto empírico são os desenhos derivados da pesquisa entomológica, pertencentes ao arquivo do Instituto Oswaldo Cruz e aos arquivos pessoais de seus pesquisadores Herman Lent e José Jurberg, especialistas no estudo dos insetos transmissores da doença de Chagas, os barbeiros.

A pesquisa se desenvolveu em duas vertentes. Em uma delas, empreendeu-se uma análise documental nos arquivos selecionados, em busca de informações sobre os desenhistas contratados, os pesquisadores que também desenhavam e os vínculos que os desenhos guardam com áreas importantes de desenvolvimento de pesquisas na instituição, o que resultou em um quadro contextual da produção e do uso desses documentos.

$\mathrm{Na}$ outra vertente da pesquisa, procurou-se problematizar o desenho científico como documento iconográfico. À luz da arquivologia e articulando dados da pesquisa de caráter histórico sobre as funções desse documento no contexto institucional, os resultados conduzirão a uma proposta metodológica para tratamento arquivístico desses registros, tendose em conta as dimensões autorais, as técnicas empregadas, as relações documentais entre a iconografia e os demais registros envolvidos no desenvolvimento da atividade de pesquisa entomológica, além da linguagem adequada para descrever seus conteúdos.

Este texto apresenta uma análise preliminar dos avanços da pesquisa em seu primeiro ano de atividades, em relação à primeira vertente da pesquisa.

\section{A ilustração científica e a entomologia no Instituto Oswaldo Cruz}

Elemento constitutivo da produção científica moderna, mais especificamente da sua comunicação, considera-se a ilustração científica como a 
representação gráfica do objeto de estudo. 0 estreito vínculo desse discurso visual com o escrito está presente nas diversas finalidades da comunicação científica, seja para validar perante os pares a veracidade ou existência do objeto/fenômeno ou para divulgá-lo a um público maior.

As modalidades de ilustração científica diversificaram-se conforme foram ampliados os dispositivos técnicos para sua elaboração. Atualmente, o resultado é um grande elenco de modalidades ilustrativas sob a forma estática. A pesquisa em foco se concentra em uma forma ilustrativa presente na comunicação científica desde os seus primórdios - o desenho -, o qual, a despeito dos recursos visuais de que se dispõe contemporaneamente para construção do discurso na comunicação científica, prossegue sendo considerado de grande relevância.

Em sintese, a ilustração científica é a materialização gráfica de um corpo de ideias de gênese cientifica, válidas à época e que traduz o modo como a Ciência vê ou compreende o mundo natural, passando no imediato a constituir informação com valor documental e arquivistico. Se, regra geral, constitui complemento à informação escrita, assume por vezes a relevância de ser também suplemento em alguns outros documentos descritivos - principalmente porque é uma excelente ferramenta para revelar padrões repetitivos, ou regularidades que possam constituir modelos explicativos; duma forma ou doutra, faz parte integrante e indissociável do discurso científico, desde a sua gênese. (Correia, 2011, p.232-3)

A botânica e a zoologia estão entre as ciências que recorrem ao desenho científico. Na descrição de espécies, por exemplo, à exatidão e à objetividade atribuídas ao desenho científico soma-se a possibilidade de compor certos detalhamentos ou perspectivas na representação visual do objeto que só ele permite.

Esse aspecto explica, em parte, um outro nível de recorte no estudo, relativo à entomologia como a área científica a ser abordada. Também pesou 
7.

Sobre aparatos e técnicas utilizadas na ilustração científica ver, entre outros, Pereira, 2016.

8.

Nesse mesmo ano foi fundada a London School of Tropical Medicine, onde se coroou a "confluência entre os novos estudos microbianos, os estudos clássicos realizados sobre doenças dos climas cálidos e os estudos de entomologia e parasitologia" (Caponi, 2004, p.430). nessa escolha a tradição da pesquisa entomológica no IOC, presente na instituição desde sua criação, que mantém até hoje relevante produção e encontrase expressivamente representada em arquivos sob a guarda do DAD. Entre os desenhos presentes nesses arquivos, a quase totalidade refere-se à descrição morfológica das diferentes fases do ciclo biológico de insetos - ovo, larva, pupa, ninfa e adulto -, transmissores ou não de doenças, e data das décadas de 1900 a 1980. Os desenhos foram elaborados com o apoio de aparatos tecnológicos como microscópios, lupas e outros equipamentos imprescindíveis para a observação do exemplar a ser representado. Para sua confecção utilizaram-se consagradas técnicas de pintura à mão livre como grafite, nanquim, lápis de cor e guache?

0 início das pesquisas com insetos no IOC deve ser compreendido a partir de um movimento médico-sanitário internacionalizado em fins do século XIX, que buscava descortinar as causas e os efeitos provocados por doenças até então pouco conhecidas. Essas geravam sérios entraves para as relações socioeconômicas entre as potências do Velho Mundo e suas possessões tropicais (Benchimol, 1990). Nesse sentido, as descobertas feitas por pesquisadores europeus nas colônias da Ásia e da África, sobre etiologia e forma de transmissão da malária, levaram ao surgimento de uma nova disciplina científica: a medicina tropical. Entre essas descobertas estão as de Alphonse Laveran sobre um hematozoário, inicialmente denominado Oscillaria malariae (1891) e depois Plasmodium, e de Ronald Ross, que estudava na Índia casos da doença em aves e concluiu, em 1898, que a malária era transmitida por mosquitos hematófagos do gênero Culex ${ }^{8}$.

No Brasil, Adolpho Lutz, então diretor do Instituto Bacteriológico de São Paulo, constatou a presença do protozoário causador da malária no sangue dos trabalhadores da construção da ferrovia que ligaria o porto de Santos à cidade de São Paulo. Lutz concluiu que a transmissão da doença se dava por uma nova espécie do gênero Anopheles. Estudos posteriores também associaram a transmissão da 
febre amarela aos insetos hematófagos e introduziram, nos países que realizavam pesquisas sobre combate às febres tropicais, entre eles o Brasil, o interesse pela entomologia médica, que reuniu zoólogos, veterinários e botânicos nas pesquisas de bacteriologia (Benchimol e Silva, 2008).

Ainda na década de 1890 Oswaldo Cruz começou a atuar na saúde pública, ao engajar-se no combate à epidemia de cólera que grassava no Vale do Paraíba. Na ocasião conheceu Adolpho Lutz, com quem iniciou intercâmbio científico. Anos depois Oswaldo Cruz assumiu a direção técnica do recém-criado Instituto Soroterápico Federal, encarregado da produção de soros e vacinas e sediado em Manguinhos, no Rio de Janeiro. Em seus laboratórios desenvolviam-se também pesquisas sobre doenças que acometiam a população carioca, entre as quais a malária e a febre amarela (Benchimol, 1990).

Em 1901 Oswaldo Cruz publicou o resultado de suas pesquisas sobre mosquitos observados em focos de malária dos "arredores" do Rio de Janeiro. Intitulado "Contribuição para o estudo dos culicídios do Rio de Janeiro" (Cruz, 1901), foi o primeiro artigo a ter a chancela "Trabalho do Instituto de Manguinhos" e trazia ilustrações feitas pelo próprio pesquisador. Publicado no periódico Brazil-Médico, atraiu a atenção de Adolpho Lutz, que teceu os seguintes comentários:

Li seu artigo sobre um anopheles novo. Agradecendo-lhe a boa intenção de o chamar por meu nome, devo-lhe dizer que o nome a. Lutzii já está pré-ocupado por Theobald que assim chamou uma das duas novas espécies que mandei daqui já faz muito tempo. A outra foi chamada a. albimannos e desconfio que seja idêntica com a espécie descoberta pelo colega; se me mandar um exemplar poderei ser mais positivo. Sei que ocorre perto da capital federal. Tenho-o de meia dúzia de lugares.

A grande obra do British Museum sobre os mosquitos de todo o mundo já deve ter aparecido no mês passado. Estou esperando-a cada dia. Será bom esperar esta obra fundamental para qualquer publicação 
9.

Carta de 30 de novembro de 1901. Arquivo Oswaldo Cruz. Série Correspondência. Acervo COC/Fiocruz sobre o assunto. (...) Na América do Sul deve haver pelo menos 4 anopheles a. albitarsis e argyritarsis são idênticos e o seu território vai das Antilhas até ao Rio da Prata, como acontece com vários Culex (entre outros taeniatus e fatigans) ${ }^{9}$.

Vale observar que as pesquisas de Adolpho Lutz sobre os insetos da ordem Diptera o inseriram em uma rede internacional de colaboradores do British Museum, para elaboração de um catálogo de mosquitos de todo o mundo. Ele foi também um dos principais interlocutores de Frederick Theobald, entomologista inglês que coordenava o projeto do catálogo, sobre assuntos de taxonomia, tendo proposto um esquema taxonômico original para a família Culicidae, que corresponde aos mosquitos e pernilongos (Sá, 2008).

Em 1903 Oswaldo Cruz assumiu a Diretoria Geral de Saúde Pública e deu início às campanhas sanitárias na capital federal. No mesmo ano defendeu, no V Congresso Brasileiro de Medicina e Cirurgia, a teoria culicidiana, com base na qual conseguiria debelar os surtos de febre amarela que atingiam a cidade, provocando mortes e prejuízos ao comércio exterior do país.

A descoberta da doença de Chagas, em 1909, foi um dos marcos nas pesquisas em medicina tropical do Brasil, com forte impacto no ordenamento do IOC, no que se refere à sua atuação no campo da entomologia médica. Nas décadas subsequentes, pesquisadores do Instituto como Arthur Neiva, Adolpho Lutz, Ângelo da Costa Lima, Lauro Travassos e Herman Lent prosseguiram na coleta e nos estudos de mosquitos, barbeiros, piolhos, borboletas, moscas, flebótomos e besouros, que resultaram na Coleção Entomológica, reconhecida como uma das mais importantes da América Latina. Os espécimes foram inicialmente trazidos pelos pesquisadores, que se engajaram nas campanhas sanitárias e expedições científicas promovidas pela instituição. As pesquisas conectaram a ciência praticada em Manguinhos com as questões de saúde que a medicina tropical associada à entomologia elucidavam (Fonseca Filho, 
10.

Sede histórica do Instituto Oswaldo Cruz, construida em estilo mourisco entre 1903 e 1909 pelo arquiteto Luiz de Moraes Jr., sob orientação de Oswaldo Cruz (Oliveira, 2003).

11.

Parte da coleção foi enviada a outras instituições como o Museu de Zoologia, da Universidade de São Paulo e o Museu Nacional, da Universidade Federal do Rio de Janeiro.

12.

Parte desse acervo encontra-se digitalizado e disponível para consulta online (http://ceioc. fiocruz.br).
1973). Os estudos em entomologia médica também levaram a uma expertise sobre a taxonomia dos insetos a partir das contribuições desses pesquisadores (Sá, 2008).

Os estudos realizados na instituição geraram vasta documentação, na qual se destacam, para os propósitos deste texto, os desenhos científicos elaborados desde o então Instituto Soroterápico Federal, por desenhistas e pesquisadores. Entre esses últimos, Fabio Leoni Werneck, Hugo de Souza Lopes e Octávio Mangabeira Filho, também autores dos desenhos que ilustravam seus artigos. Esses documentos representam importante testemunho da trajetória da pesquisa no IOC, que teve no mencionado artigo de Oswaldo Cruz seu marco inaugural, alinhando a instituição à tradição de representar graficamente os mais variados tipos de materiais encontrados na biodiversidade brasileira e em outros países, em especial moluscos, fungos, protozoários, bactérias, insetos e helmintos. A preservação desse material deuse inicialmente com a formação de coleções de importância médico-sanitária que, com o passar dos anos, adquiriram status de coleções de pesquisa, nas quais se insere a mencionada Coleção Entomológica.

Em constante expansão, a Coleção Entomológica passou a ocupar o segundo andar do Pavilhão Mourisco ${ }^{10}$ nos anos 1950. Vinte anos depois, durante o regime militar, a coleção sofreria as consequências do episódio de cassação e aposentadoria compulsória de pesquisadores do IOC, quando três entomologistas foram afastados: Herman Lent, Hugo de Souza Lopes e Sebastião José de Oliveira. Na ocasião, os armários que abrigavam a coleção foram transferidos para o porão do Hospital Evandro Chagas, situado no campus de Manguinhos, onde permaneceram em péssimas condições (Oliveira e Messias, 2005) ${ }^{11}$.

Em 1977 a Coleção Entomológica retornou a seu lugar de origem no Pavilhão Mourisco, ainda que desfalcada de vários espécimes irremediavelmente perdidos. A partir do final dos anos 1980 passou por um processo de ampliação e modernização e atualmente possui cerca de cinco milhões de espécimes ${ }^{12}$. 
13.

Ver, a respeito, Fundação Oswaldo Cruz, 2001, e Edler, 1995.

14.

Ver, a respeito, Almeida et al., 2001.
Quanto ao desenho científico, em que pese sua importância para as pesquisas realizadas no IOC, informações mais sistematizadas sobre tal atividade seguem sendo necessárias. A Casa de Oswaldo Cruz (COC) investiu em projetos que organizaram e tornaram acessíveis acervos documentais estreitamente relacionados às coleções científicas ${ }^{13}$. Da mesma forma, produziu importante documentação oral na forma de entrevistas, com atores institucionais que atuaram nas áreas de estudos responsáveis pela organização dessas coleções ${ }^{14}$.

Contudo, a respeito do funcionamento dos serviços auxiliares dos trabalhos científicos, entre os quais o de desenho é dos mais antigos e longevos, pouca informação foi colhida e sistematizada. Por tal razão, a pesquisa das fontes documentais sobre as ilustrações científicas teve início com o levantamento, no arquivo do IOC, de documentos que informam sobre esse processo de trabalho, além de analisar a trajetória institucional dos responsáveis pela produção dos desenhos, suas relações com os pesquisadores, rotinas de serviço, principais formas de divulgação dos desenhos e suas funções para a pesquisa com insetos.

Embora ainda em curso, o levantamento e a análise das fontes suscitam questões e hipóteses que é conveniente divulgar, com o propósito, sobretudo, de receber contribuições de pesquisadores dedicados a temas congêneres. Antes, porém, de nos determos sobre os resultados até agora alcançados, cabe esclarecer sobre as diretrizes que orientam metodologicamente a pesquisa e melhor delimitam seu objeto.

\section{Perspectivas de análise}

Diversas perspectivas de análise podem ser adotadas na abordagem de usos e funções das ilustrações nas atividades científicas. A mesma pluralidade de enfoques está presente nos estudos sobre a representação figurativa como elemento constituinte da produção e disseminação científicas modernas.

É possível, por exemplo, investigar essa rica relação avaliando as imagens produzidas manualmente 
quanto aquelas provenientes dos principais dispositivos técnicos de representação visual, mais amplamente disponíveis a partir do século XIX, como a fotografia. Fabris (2002) já observava que um novo valor vem a ser adicionado nas representações visuais obtidas pelo dispositivo fotográfico nos trabalhos científicos, relacionado a um "certificado de presença” engendrado pelas qualidades sígnicas da fotografia. Tal valor está na base do uso instrumental do efeito de "realismo" proporcionado por essa imagem, com impactos no estatuto da representação figurativa feita à mão.

Pode-se também estudar tais imagens em sua dimensão de elemento mediador do conhecimento científico ao lado do texto. Hoje as interconexões entre a escrita científica e as ilustrações que a acompanham são debatidas por linhas de estudos que discutem as dimensões artísticas, pedagógicas, de disseminação e divulgação do conhecimento científico, todas voltadas para a análise das práticas de ilustrar por meio de imagens. As funções das ilustrações parecem ser tema que gravita em torno dessas discussões (Fabris e Kern, 2006; Oliveira, Conduru, 2004).

É possível também abordar as conexões entre ciência e arte em uma perspectiva da criação do ofício de desenhista ou ilustrador científico. Segundo Heizer (2015, p.23), ainda no século XVII as instruções de viagens dos naturalistas "continham não apenas o quê, mas especialmente como desenhar", pressupondo um rol de ideias e procedimentos que conformavam a prática da produção técnica e artística, na qual as ilustrações foram forjadas como auxílio descritivo.

No Brasil, a institucionalização da ciência inicia-se no século XIX e consolida-se no século seguinte, quando ganham corpo importantes centros de produção científica (Dantes, 1980; Schwartzman, 2001). Nesse processo, as práticas científicas são também desenvolvidas de forma a dotar os trabalhos de rigor e excelência. Certos ofícios são requeridos como peças relevantes ao desenvolvimento dos trabalhos científicos em seus cenários principais - laboratórios e trabalhos de campo -, sobretudo para 
comporem o discurso científico a ser registrado, traduzido figurativamente, utilizado como prova, divulgado, ensinado e, por fim, arquivado como evidência. Nos espaços institucionais edificados para o trabalho científico, todas essas funções estão embutidas em setores de desenho, fotografia, cartografia e na presença de profissionais habilitados para exercerem a função de "tradutores".

Esse fenômeno ocorreu também no Instituto Oswaldo Cruz, criado no contexto de transformação do próprio campo científico e consubstanciado no incremento de pesquisas básicas e atividades em laboratório, preconizadas pela medicina experimental. 0 contexto de desenvolvimento dos trabalhos científicos, em tais bases, confere à ilustração científica o estatuto de atividade integrante da estrutura institucional. Tais perspectivas estão presentes neste estudo, que busca lançar luz sobre as lógicas de produção e usos da ilustração científica em uma cultura institucional muito particular, a do IOC, tendo como base os registros documentais remanescentes dessa atividade.

\section{Notas da pesquisa em curso}

Antecederam a pesquisa ao arquivo do IOC o levantamento e estudo de seus regimentos, aprovados por decretos ou outros atos normativos do Executivo, de 1907 a 1962. A etapa resultou na montagem de organogramas que situam o serviço de desenho nas várias estruturas que teve a instituição. Chama atenção o fato de já constar o cargo de desenhista no quadro de funcionários aprovado pelo decreto n. 1.802, de 12 de dezembro de 1907, que cria o Instituto de Patologia Experimental e o formaliza como entidade de pesquisa médico-experimental ao mencionar, entre suas competências, o "estudo das moléstias infectuosas e parasitárias do homem, dos animais e das plantas" (Brasil, 1907).

Os regimentos e organogramas contribuíram na análise formal da atividade de desenho na instituição ao longo do tempo e à medida que se ampliou sua estrutura organizacional. Por sua vez, para o 
15.

Tipo documental: "configuração que assume uma espécie documental, de acordo com a atividade que a gerou" (Camargo e Bellotto, 1996, p.80). desenvolvimento da pesquisa, ela orientou o levantamento, no arquivo IOC, de séries e outros conjuntos documentais pertinentes ao objeto de análise.

Iniciou-se, então, o levantamento de documentos do IOC mais estritamente vinculados à temática do projeto. Por ser um arquivo institucional, ele reúne documentos produzidos ou acumulados no cumprimento das funções do organismo ao longo do tempo. Até o momento, o levantamento concentrouse nos documentos administrativos, com o intuito de encontrar indícios sobre a organização e a operação das atividades de desenho. Os tipos documentais ${ }^{15}$ que compõem o conjunto em análise trazem informações sobre diretrizes e políticas emanadas da direção da entidade e de outros níveis hierárquicos de tomadas de decisão, bem como orientações sobre rotinas e processos de trabalho, estabelecidas por escalões inferiores.

\section{Arquivo IOC: relatórios anuais do Serviço de Administração Geral, ofícios, portarias e ordens de serviço}

Nos relatórios foram encontradas ocorrências institucionais diversas e de relevância variada, que marcaram o transcurso de um ano, bem como apresentam-se as principais ações e atividades realizadas. Como os serviços auxiliares estiveram vinculados, durante muito tempo, à área administrativa do IOC, pressupôs-se que seus relatórios anuais seriam fonte privilegiada de informações. Porém os resultados do levantamento - que abrangeu, até o momento, de 1908 a 1970 - não reverteram em informações relevantes para os propósitos da pesquisa. Pôde-se ponderar que, devido à sua natureza, esse tipo documental tende a registrar dados consolidados e de caráter mais geral. Contudo a escassez de documentos específicos sobre os serviços de desenho nas demais séries do arquivo do IOC leva-nos a suspeitar de pouca formalidade nos processos do trabalho de ilustração científica, talvez mais marcados pela interação direta entre desenhista e pesquisador que regulados por instruções formais. 
16.

Ofício: "aviso e ofício são modalidades de comunicação oficial praticamente idênticas. A única diferença entre eles é que o aviso é expedido exclusivamente por Ministros de Estado, para autoridades de mesma hierarquia, ao passo que o ofício é expedido para e pelas demais autoridades. Ambos têm como finalidade o tratamento de assuntos oficiais pelos órgãos da Administração Pública entre si e, no caso do ofício, também com particulares" (Brasil, 2002).

17.

Portaria: "É o instrumento pelo qual ministros ou outras autoridades expedem instruções sobre a organização e funcionamento de serviço e praticam outros atos de sua competência” (Brasil, 2002).

18.

Ordem de serviço:

"Determinação técnica ou administrativa dirigida a responsáveis por obras ou serviços" (SAUSP, 1997, p.28).
Outros tipos documentais ${ }^{15}$ consultados do arquivo permanente do IOC foram ofícios ${ }^{16}$ (19081970), portarias ${ }^{17}$ e ordens de serviço ${ }^{18}$ (1939-1970).

Em ofícios, portarias e ordens de serviço localizam-se informações sobre providências de trabalho, como viagens em expedições que, uma vez associadas a informações de outras fontes, ajudarão a compreender como se davam a mobilidade dos desenhistas e pesquisadores entre cargos e funções e as rotinas do ofício de ilustração no IOC.

\section{Arquivo IOC: assentamentos funcionais}

Nos assentamentos funcionais inscrevem-se e transcrevem-se atos, fatos, titulações e demais aspectos relativos à vida funcional dos empregados, desde sua admissão até sua transferência, demissão ou aposentadoria. No que concerne aos desenhistas, essa fonte de pesquisa ganha ainda mais relevância diante dos poucos registros documentais, no arquivo do IOC, relativos a configuração e funcionamento dos serviços de desenho na instituição. Nela revela-se, ao menos em parte, a face do desenhista como funcionário ou colaborador da instituição por meio de seu percurso, ao longo dos anos, no exercício de funções e cargos próprios ou não de seu ofício. Também nos assentamentos constam eventualmente dados de filiação, data e local de nascimento, casamento e morte, nomes de cônjuge e filhos, além de transcrições de elogios ao desenhista por sua atuação em expedições científicas e outras missões, ou mesmo pela excelência do conjunto de seu trabalho.

Os seguintes profissionais foram identificados no desempenho do cargo ou função de desenhista, entre as décadas de 1900 a 1960: Antonio Leal Rodrigues; Antonio Viegas Pugas; Carl Rudolph Fischer; Edith da Fonseca Nogueira Penido; José Tavares de Lacerda Sobrinho; Luiz Augusto Cordeiro; Luiz Kattenbach; Manoel Castro e Silva; Raymundo Honório Daniel; Raymundo Porciúncula de Morais; Renée Ferreira de Melo; e Walter Alves da Silva. A título de exemplo, mencionamos os resumos da 
19.

Há dois registros de data de ingresso do desenhista no IOC, referindo-se um deles a 1 de agosto de 1915 (Livro 2, fl.2) e outro a 1 de fevereiro de 1916 (Livro 1, fl.97).

20.

Sobre o periódico, ver Weltman, 2002 e Martins, 2003

21.

Quatro dos oito artigos publicados no primeiro número de Memórias contêm ilustrações, todas elas desenhos. Apenas um (Lutz e Neiva, 1909), reproduzindo a anatomia de um inseto, é assinado. Seu autor é Castro Silva, o primeiro a ser contratado como desenhista no IOC, conforme mencionado. trajetória funcional de dois deles, elaborados com base em seus assentamentos funcionais:

- Manoel Castro e Silva: primeiro desenhista contratado no IOC, em 1906. Durante o surto epidêmico da gripe espanhola, em 1918, foi designado para trabalhar no hospital e pronto socorro de Ramos (Rio de Janeiro), tendo recebido elogios de Carlos Chagas e do diretor do hospital, pelo trabalho realizado. Em 1921 foi designado para exercer o cargo de bibliotecário enquanto o efetivo desse cargo estivesse em outra função. Retornou ao cargo de desenhista em 1931, mesmo ano em que esse cargo passou a denominar-se desenhista chefe. Faleceu em 1934.

- Raymundo Honorio Daniel: admitido em 1915 ou 1916 como servente ${ }^{19}$. Em 1919 tomou posse como servente de laboratório, função que exerceu até 1921. Readmitido na instituição como desenhista em 1927. Em 1931 tomou posse e entrou em exercício na função de auxiliar de desenhista. Em 1934 integrou, na mesma função, uma lista de mensalistas contratados por um ano. Dispensado em 1944.

Os assentamentos funcionais também serão analisados para a elaboração do perfil biográfico dos pesquisadores que produziram desenhos encontrados nos arquivos em estudo.

\section{Memórias do Instituto Oswaldo Cruz}

Fonte documental da maior relevância para os propósitos da pesquisa é o periódico Memórias do Instituto Oswaldo Cruz, que teve seu primeiro número publicado em 1909 e permanece corrente. Memórias foi o primeiro periódico das áreas biológica e biomédica do país, criado por iniciativa de Oswaldo Cruz para a comunicação da produção científica de pesquisadores da instituição ${ }^{20}$.

Os números da revista são objeto de prospecção para os artigos ilustrados. A sistematização dos dados abrange todos os tipos de ilustrações e todos os artigos, independentemente da área científica, de 
22.

0 artigo, de Stanislaus von Prowasek e Henrique de Beaurepaire Aragão (Prowazek e Aragão, 1909), apresenta desenho e microfotografia do micróbio da varíola, ambos sem crédito de autoria.

23.

A Base Arch é o repositório de informações sobre o acervo arquivístico da Casa de Oswaldo Cruz (http://arch.coc.fiocruz. br). A incorporação das notas biográficas a ela se dará pela inserção dos desenhistas ao Registro de Autoridade, que fornece descrições de entidades coletivas, pessoas e familias, sendo elas produtoras de modo a ser utilizada, no futuro, em abordagens de outras modalidades de representação iconográfica presentes nos artigos, como fotografias, microfotografias, gráficos e mapas.

Até agora foram analisados os 25 primeiros volumes da revista, publicados até 1931. A presença de ilustrações nos artigos, observada desde o primeiro número $^{21}$, ocorre com grande frequência. Dos 364 artigos publicados nos mencionados volumes, 256 (c.72\%) são ilustrados. Desse total, 189 (c.74\%) apresentam desenhos, acompanhados ou não de outras formas ilustrativas. Os desenhos predominam como modalidade de ilustração até o final da década de 1920 e pode-se observar nos artigos até agora analisados a convivência crescente deles com a fotografia e a microfotografia, introduzidas pela primeira vez em um artigo de $1909^{22}$.

Os desenhos de artigos de entomologia ainda devem passar por nova análise, para complementar a coleta de dados específicos para atender aos propósitos da pesquisa aqui tratada. Além de embasá-la, os resultados desse levantamento alimentarão os instrumentos de pesquisa com dados sobre a publicação de desenhos integrantes do acervo arquivístico sob a guarda do DAD. A importância dessa informação se dá porque a publicação do desenho em um artigo científico atesta ter sido ele validado como representação correta do fenômeno ou objeto em questão.

\section{Demais fontes a explorar}

Além do arquivo do IOC o projeto prevê a pesquisa nos arquivos de Herman Lent e José Jurberg. Nesses últimos ocorre interpenetração das esferas pública e privada das trajetórias de vida de seus titulares e neles encontram-se documentos relacionados à sua atuação profissional, entre eles desenhos científicos: “A prática de 'embaralhar' a massa de papéis públicos e privados e levá-los para outro destino, seja um novo local de trabalho seja a própria residência, é comum entre aqueles que exerceram algum tipo de função pública” (Lima, Brito e Santos, 2014, p.191). 
arquivos ou a esses de algum modo relacionadas.

24.

Sobre esse tema ver principalmente Santos, 2010.
Outras fontes arquivísticas relevantes foram as entrevistas com curadores, pesquisadores e técnicos que trabalharam ou trabalham com coleções científicas da Fundação Oswaldo Cruz (Fiocruz), bem como de seus entomólogos que registraram em depoimento seu testemunho sobre a ilustração como elemento de comunicação de seus trabalhos e sobre sua relação com desenhistas. As entrevistas compõem o acervo do Programa de História Oral do Departamento de Pesquisa da COC e encontram-se sob a guarda do $\mathrm{DAD}$, que os disponibiliza para consulta. Elas ganham ainda mais importância diante da provável escassez de documentos relativos à atividade de desenho no IOC e pelo que podem revelar de significados atribuídos por atores diretamente envolvidos na produção e no uso dos desenhos. Espera-se, portanto, que tais fontes revelem mais sobre a relação entre as coleções e os desenhos científicos, entre pesquisadores e desenhistas, bem como sobre o próprio ofício desses últimos na instituição.

Todas as fontes documentais serão também exploradas para a composição de notas divulgadas por meio da base $\mathrm{Arch}^{23}$ e outras ferramentas de pesquisa do acervo em foco.

\section{Considerações finais}

A Fiocruz, ao lado de outras instituições de pesquisa congêneres, detém importante acervo de ilustrações e desenhos que se relacionam com suas coleções científicas, cuja produção é fruto dos processos de trabalho de divulgação e de disseminação da ciência. Hoje apartados das lógicas que estruturaram as circunstâncias pelas quais foram produzidos, esses documentos correm o risco de terem sua força de registro de memória reduzida, na medida em que são organizados e descritos em conjunto com outros, sem que se dê o devido destaque às suas especificidades e às conexões que mantêm com demais registros arquivísticos relativos à pesquisa entomológica no IOC.

A pesquisa a que se refere este artigo foi motivada pela vontade de pesquisar o tempo e as circunstâncias que propiciaram os trabalhos de ilustração 
científica em Manguinhos e sistematizar os resultados em instrumentos de pesquisa, tais como a base de dados onde os arquivos são descritos ou outros a serem produzidos. Ao buscarmos uma abordagem inovadora sobre esse acervo e sobre o desenho especificamente, pretendemos produzir um conhecimento sobre suas condições de produção que assegurarão a esses documentos simultaneamente os estatutos de evidência e memória de sua entidade produtora - o IOC. Tal abordagem se insere em reflexões e questionamentos a respeito dos arquivos produzidos pela ciência contemporânea e os desafios que eles impõem à arquivologia nas funções de preservação e gestão dessa memória ${ }^{24}$.

Do ponto de vista mais pragmático, o resultado da pesquisa dotará as formas de representação desses documentos - campos descritivos nas bases de dados, dados informacionais específicos e até mesmo termos de indexação para seu acesso - de novos elementos relacionados às especificidades de linguagem e de conteúdo desse gênero documental, a iconografia. Os documentos iconográficos são também portadores de sentido em si mesmos, possuem seus próprios dispositivos técnicos e protocolos formais de produção, estão inscritos em uma história (técnica, artística) que ultrapassa os limites institucionais (ao mesmo tempo que são por eles constrangidos). 0 desafio que se impõe, então, é conciliar abordagens técnicas aparentemente divergentes de modo a, por um lado, representar esses documentos na sua relação orgânica com os demais de seu conjunto original e, por outro, evidenciar os elementos que lhes são específicos. As demandas atuais de informação desses documentos, provindas de um público cada vez mais diversificado, exigem a busca por essa conciliação. 
Imagens:

Colaboraram na elaboração deste artigo as bolsistas Lara Rodrigues de Brito Pinheiro e Maria Carolina Silva Borges. A edição das imagens é de Roberto Jesus Oscar.

\section{Figura 1}

Larva do mosquito Dendromyia personata, descrito por Adolpho Lutz. Desenhos de Manoel de Castro e Silva, 1908.

\section{Figura 2}

Mosquito adulto de Myzorhynchella parva, descrito por Carlos Chagas em 1907.

Desenho de Manoel de Castro e Silva, 1908.

Figura 3

Hoplopleura travassosi, piolho fêmea parasita de mamíferos, descrito por Fábio Leoni Werneck. Desenho do próprio pesquisador, 1932.

\section{Figura 4}

Estruturas da genitália, palpo e asa de Flebotomus bachiphallus (atual Lutzomyia brachiphalla). Desenhos de Octávio Mangabeira Filho, pesquisador de insetos vetores das leishmanioses, 1941.

\section{Figura 5}

Rhodnius neglectus, espécie de barbeiro vetor da doença de Chagas, descrito por Herman Lent. Desenho de Antonio Viegas Pugas, 1954.

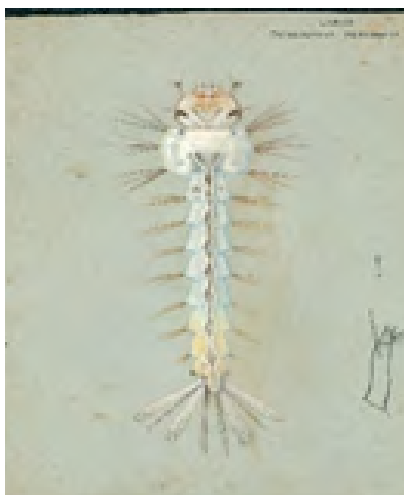

Figura 1

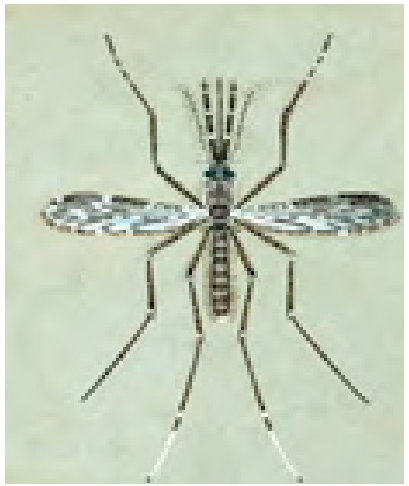

Figura 2

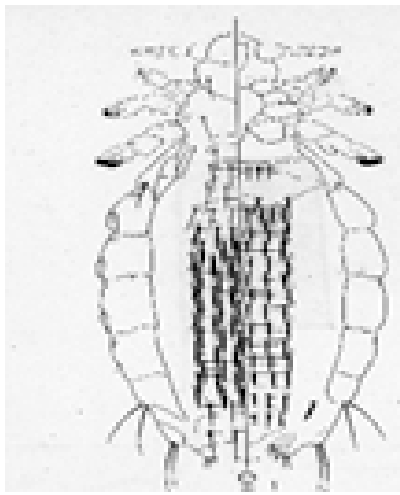

Figura 3

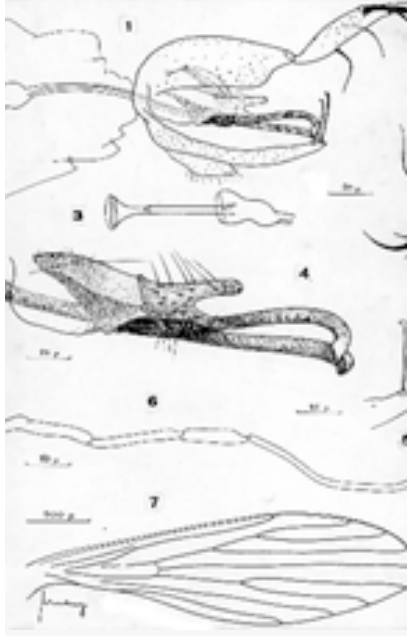

Figura 4

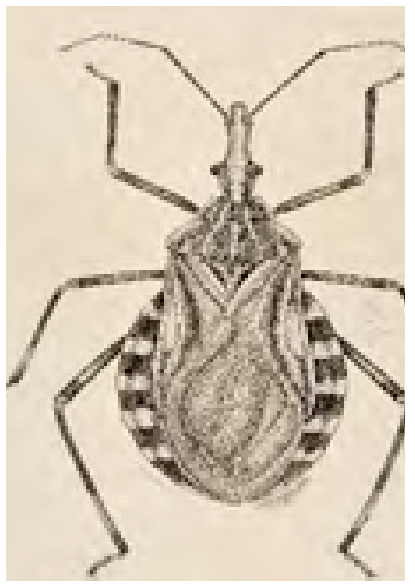

Figura 5 
ALMEIDA, A. B. S. et al. (Org.). Memória das coleções científicas do Instituto Oswaldo Cruz da Fundação Oswaldo Cruz: acervo de depoimentos. Rio de Janeiro: Fiocruz, 2001.

BENCHIMOL. J. L. (Coord.). Manguinhos do sonho à vida: a ciência na belle époque. Rio de Janeiro: Casa de Oswaldo Cruz, 1990.

; SILVA, A. F. C. Ferrovias, doenças e medicina tropical no Brasil da Primeira República. Hist. cienc. saúde-Manguinhos [online], 2008, v.15, n.3, p.719-62.

BRASIL. Decreto n. 1.802, de 12 de dezembro de 1907. Cria o Instituto de Patologia Experimental de Manguinhos.

BRASIL. Presidência da República. Manual de redação da Presidência da República. 2. ed. rev. e atual. Brasília: Presidência da República, 2002.

CAMARGO, A. M. A.; BEllotTO, H. L. (Coord.). Dicionário de terminologia arquivística. São Paulo: Associação dos Arquivistas Brasileiros, 1996.

CAPONI, S. Trópicos, micróbios e vetores. In: MARTINS, R. A. et al. (Ed.). Filosofia e história da ciência no Cone Sul: $3^{\circ}$ Encontro. Campinas: AFHIC, 2004. p.429-37.

CORREIA, F. A ilustração científica: "santuário" onde a arte e a ciência comungam. Visualidades, jul.-dez. 2011, v.9, n.2, p.221-39.

CRUZ, 0. G. Contribuição para o estudo dos culicidios do Rio de Janeiro. Brazil-Médico, Rio de Janeiro, 1901, v.15, n.43, p.423-6.

DANTES, M. A. M. Institutos de pesquisa científica no Brasil. In: FERRI, M. M.; MOTOYAMA, S. (coord.). História das ciências no Brasil. São Paulo: EPU; Ed. USP, 1980. p.343-80.

EDLER, F. Fontes alternativas para uma história da ciência. Hist. cienc. saúde-Manguinhos [online], nov. 1994-fev.1995, v.1, n.2, p.89-100.

FABRIS, A. Atestados de presença: a fotografia como instrumento científico. Locus, Revista 
de História. Juiz de Fora, 2002, v.8, n.1, p.29-40.

; KERN, M. L. B. (Org.). Imagem e conhecimento. São Paulo: Edusp, 2006.

FONSECA FILHO, O. A escola de Manguinhos: contribuição para o estudo do desenvolvimento da medicina experimental no Brasil. São Paulo: EGRT, 1973.

FUNDAÇÃO OSWALDO CRUZ. Casa de Oswaldo Cruz. Departamento de Arquivo e Documentação. Fundo Instituto Oswaldo Cruz: inventário dos documentos das coleções científicas. Rio de Janeiro: Fiocruz, 2001.

HEIZER, A. A ilustração científica: entre a aventura e o registro. In: ORMINDO, P.; HEIZER, A.; PENNA, C. G.; SAlLES, P. (Org.). Mata Atlântica: ciência e arte. Rio de Janeiro: Hólos Consultores Associados; 2015. p.23-31.

LIMA, A. L. G. S.; BRITO, V. M., Santos PRE. A escrita da ciência: do trabalho à vida pessoal. In: Iglesias F, Santos PRE, Martins RB (org.). Vida, engenho e arte: o acervo histórico da Fundação Oswaldo Cruz. Rio de Janeiro: Fiocruz/Casa de Oswaldo Cruz; 2014. p.189-233.

LUTZ, A.; NEIVA, A. Erephopsis auricincta: uma nova mutuca, da subfamília: Pangoninae. Mem. Inst. Oswaldo Cruz [online]. 1909, v.1, n.1; p.12-3.

MARTINS, R. B. Do papel ao digital: a trajetória de duas revistas brasileiras [Dissertação de mestrado]. Rio de Janeiro: Instituto Brasileiro de Informação em Ciência e Tecnologia/Escola de Comunicação da Universidade Federal do Rio de Janeiro, 2003.

OLIVEIRA, B. T. (Coord.). Um lugar para a ciência: a formação do campus de Manguinhos. Rio de Janeiro: Ed. Fiocruz; 2003.

OLIVEIRA, R. L.; CONDURU, R. Nas frestas entre a ciência e a arte: uma série de ilustrações de barbeiros do Instituto Oswaldo Cruz. Hist. cienc. saude-Manguinhos [online], Maio-Ago. 2004, v.11, n.2, p.89-100. 
OLIVEIRA, S. J.; MESSIAS, M. C. Coleção Entomológica do Instituto Oswaldo Cruz. In: Simpósio Nacional de Coleções Científica, 1, 2005, Rio de Janeiro. Caderno de resumos... Rio de Janeiro: Instituto Oswaldo Cruz, 2005. p.53-5.

PEREIRA, R. M. A. (Org.). Ilustração zoológica. Belo Horizonte: Frente Verso; 2016.

PROWAZEK, S.; ARAGAO, H. B. Estudos sobre a varíola. Mem. Inst. Oswaldo Cruz [online], 1909, v.1, n.2; p.147-58.

SANTOS, P. R. E. Arquivística no laboratório: história, teoria e métodos de uma disciplina. Rio de Janeiro: Teatral; Faperj, 2010.

SÁ, M. R. Scientific collections, tropical medicine and the development of entomology in Brazil: the contribution of Instituto Oswaldo Cruz. Parassitologia. Dec. 2008, v.50, n.3-4, p.187-97.

SCHWARTZMAN, S. Um espaço para a ciência: a formação da comunidade científica no Brasil. Brasília: Ministério da Ciência e Tecnologia; 2001.

SISTEMA DE ARQUIVOS USP (SAUSP). Glossário de espécies/formatos e tipos documentais da Universidade de São Paulo. São Paulo: SAUSP, 1997.

WELTMAN, W. L. A produção científica publicada pelo Instituto Oswaldo Cruz no período de 1900 a 1917: um estudo exploratório. Hist. cienc. saúde-Manguinhos [online], 2002, v.9, n.1, p.159-86.

Data de recebimento: 31/03/2017

Data de aprovação: 04/09/2017 
